\title{
A detection method for grass carp hemorrhagic virus (GCHV) based on a reverse transcription- polymerase chain reaction
}

\author{
Li Jun*, Wang Tiehui, Yi Yonglan, Liu Hanqin, Lu Renhou, Chen Hongxi \\ Institute of Hydrobiology, Chinese Academy of Sciences, Wuhan, 430072, China
}

\begin{abstract}
A rapid, sensitive and highly specific detection method for grass carp hemorrhagic virus (GCHV) based on a reverse transcription-polymerase chain reaction (RT-PCR) has been developed. Two pairs of PCR primers were synthesized according to the cloned cDNA sequences of the GCHV-861 strain. For each primer combination, only one specific major product was obtained when amplification was performed by using the genomic dsRNA of GCHV-861 strain. The lengths of their expected products were 320 and $223 \mathrm{bp}$, respectively. No products were obtained when nucleic acids other than GCHV-861 genomic RNA were used as RT-PCR templates. To assess the sensitivity of the method, dilutions of purified GCHV-861 dsRNA total genome $(0.01 \mathrm{pg}$ up to $1000 \mathrm{pg})$ were amplified and quantities of as little as $0.1 \mathrm{pg}$ of purified dsRNA were detectable when the amplification product was analyzed by $1.5 \%$ agarose gel electrophoresis. This technique could detect GCHV-861 not only in infected cell culture fluids, but also in infected grass carp Ctenopharyngodon idellus and rare minnow Gobiocypris rarus with or without hemorrhagic symptoms. The results show that the RT-PCR amplification method is useful for the direct detection of GCHV.
\end{abstract}

KEY WORDS: Hemorrhagic virus of grass carp (GCHV) Virus detection - Reverse transcription - Polymerase chain reaction

\section{INTRODUCTION}

Hemorrhagic virus of grass carp (GCHV) was the first fish virus isolated in China (Chen \& Jiang 1983), and about 10 additional isolations have been reported since then. The virions are ether and chloroform resistant, and non-sensitive to acid ( $\mathrm{pH} 3$ ) and alkaline (pH 10) treatment. (Mao et al. 1989, Ke 1990). They are 60 to $80 \mathrm{~nm}$ in diameter and consist of a double layered capsid containing a genome composed of 11 segments of double-stranded (ds) RNA and belong to the genus Aquareovirus (Francki et al. 1991) in the family Reoviridae. The aquareoviruses comprise one of the most rapidly growing groups of finfish viruses (Hetrick \& Hedrick 1993) and many of them are not associated with clinical disease. However, GCHV can cause a

\footnotetext{
- Present address: Lab. of Microbiotechnology, Dept of Marine Biology, College of Marine Life Sciences, Ocean University of Qingdao, Qingdao, 266003 Shandong Province, China
}

serious contagious hemorrhagic disease with high mortalities in grass carp Ctenopharyngodon idellus, black carp Mylopharyngodon piceus, topmouth gudgeon Pseudorasbora parva (Ding et al. 1991) and rare minnow Gobiocypris rarus (Wang et al. 1994). It also can replicate in silver carp Hypophthalmichthys molitrix and one kind of Chinese minnow, Hemiculter bleekeri, although no symptoms are evident (Ding et al. 1991). The virus causes large losses in fresh water fish culture facilities in China. A sensitive diagnosis method is essential if dissemination of the virus is to be controlled since no effective vaccines currently exist for its prevention. Several methods have been developed for GCHV detection, some of which utilize immunoenzyme staining ( $Y e$ et al. 1989), staphylococcal coagglutination (Yang et al. 1991), and immunofluorescence and enzyme-linked immunosorbent assays (Jiang et al. 1993). However, most of these techniques require virus propagation in a cell line which is time consuming or requires special equipment. In order to 
develop a rapid, simple and sensitive GCHV detection method, we describe the adaptation of a reverse transcription combined polymerase chain reaction to directly detect GCHV in infected fish tissues. The detection method described here promises to be useful both for early diagnosis and for epidemiological studies of GCHV

\section{MATERIALS AND METHODS}

Viruses. Strain GCHV-861 was isolated from diseased grass carp at the East \& West Lake fish farm of Wuhan (Wang et al. 1994), and the GCHV-873 strain, isolated in Shaoyang, Hunan province, China, was described by Ke (1990)

Cell lines. Two grass carp kidney cell lines were used. The GCK line was established in our laboratory by Deng \& Chen (1985), and the CIK line was obtained from the Yangzi River Fisheries Research Institute, Chinese Academy of Fisheries Sciences (Zuo et al. 1986). Cell subculturing and GCHV propagation in the cell line were carried out by the methods described by Wang et al. (1994).

Fish infection. The grass carp and rare minnows used for experimentation were less than 1 yr old and were 5 to $10 \mathrm{~cm}$ in length. They were propagated by artificial fertilization and reared in our institute's fish farm and had no history of infectious diseases. The fish were artificially infected with the GCHV-861 and GCHV-873 strains by the hyperosmotic immersion method as described by Wang et al. (1995) and were held in 501 tanks supplied with dechlorinated tap water maintained at 28 to $30^{\circ} \mathrm{C}$. Another group was exposed to the virus diluent (distilled water) and served as controls. Fish with or without hemorrhagic symptoms were sacrificed each day post-exposure. The internal organs were removed, rinsed with sterile phosphate buffered saline (PBS) to remove blood, and immediately put in $1.5 \mathrm{ml}$ Eppendorf tubes for storage at $-20^{\circ} \mathrm{C}$ until used.

GCHV purification. GCHV was purified from infected cell culture fluids, or from tissue samples of typical hemorrhagic fish, following the procedures described by Wang et al. (1993).

Extraction of genomic RNA. One volume of fresh solution $\left[0.2 \mathrm{M}\right.$ Tris- $\mathrm{HCl}_{i} \mathrm{pH} 8.0 ; 7.5 \mathrm{mM}$ EDTA $; 0.5 \%$ N-laurylsarcosine, Na-salt (Sigma Product); $200 \mu \mathrm{g} \mathrm{ml}^{-1}$ proteinase $\mathrm{K}$ ] was added to the resuspended purified virus. The mixture was incubated for 1 h at $50^{\circ} \mathrm{C}$, after which the dsRNA was extracted twice with 1 volume of saline-saturated phenol-chloroform $(1: 1)$. After centrifugation at $12000 \mathrm{rpm}$ for $5 \mathrm{~min}$, the aqueous phase was saved and rinsed with chloroform-isoamyl alcohol (24:1) solution. The aqueous phase was precipitated in liquid nitrogen for 5 to $10 \mathrm{~min}$ in the presence of $0.3 \mathrm{M}$ sodium acetate $(\mathrm{pH} 5.2)$ and 2.5 volumes of prechilled ethanol. The nucleic acids were pelleted by centrifugation at $18000 \mathrm{rpm}$ for $25 \mathrm{~min}$. The pellet was finally resuspended in TE solution (1 mM EDTA, $10 \mathrm{mM}$ Tris- $\mathrm{HCl}, \mathrm{pH} 8.0$ ) and stored at $-20^{\circ} \mathrm{C}$ until used.

Rapid tissue preparation. Each tissue sample $(0.1 \mathrm{~g})$ from infected or control fish was frozen and thawed 3 times before being homogenized in a minimal volume of STE solution (50 mM Tris- $\mathrm{HCl}, \mathrm{pH} 8.0 ; 100 \mathrm{mM}$ EDTA). The cell debris was pelleted at $12000 \mathrm{rpm}$ for $10 \mathrm{~min}$, and subsequently $40 \mu \mathrm{l}$ of the supernatant was extracted 1 time with 1 volume phenol-chloroform (1:1). The aqueous phase was extracted once with 1 volume of chloroform and once with 1 volume of ether. The resultant aqueous phase was placed in a ventilator for $15 \mathrm{~min}$, after which it could be used as the initial template for RT-PCR amplification

RT-PCR amplification. Two pairs of specific primers were synthesized according to the CDNA sequences of the cloned 6th and 9th segments which encode the major viral capsid polypeptide (Wang et al. 1993). The oligonucleotide sequences and their expected RT-PCR products are shown in Table 1. Purified viral RNA or crude tissue digest ( 2 to $5 \mu \mathrm{l}$ ) were combined with $1 \mu \mathrm{M}$ of each primer and 2 drops of mineral oil were overlayed on the mixture. The dsRNA was denatured in boiling water for $10 \mathrm{~min}$ and subsequently cooled on ice immediately after which the reverse transcription mix was added $\left(50 \mathrm{mM}\right.$ Tris- $\mathrm{HCl}, \mathrm{pH} 8.3$ at $42^{\circ} \mathrm{C}$; $10 \mathrm{mM} \mathrm{MgCl}_{2} ; 50 \mathrm{mM} \mathrm{KCl} ; 10 \mathrm{mM} \mathrm{DDT} ; 0.5 \mathrm{mM}$ Spermidine; $1 \mathrm{mM}$ dNTPs; 8U AMV reverse transcriptase) (Promega products). Reverse transcription was performed in a final volume of $20 \mu \mathrm{l}$ at $42^{\circ} \mathrm{C}$ for $45 \mathrm{~min}$ followed by a 5 min incubation in boiling water. Then $5 \mu \mathrm{l}$ cDNA products were added to $45 \mu \mathrm{l}$ PCR mixture $\left(10 \mathrm{mM}\right.$ Tris- $\mathrm{HCl} \mathrm{pH} 8.3$ at $25^{\circ} \mathrm{C} ; 2.0 \mathrm{mM} \mathrm{MgCl}_{2 i}$ $50 \mathrm{mM} \mathrm{KCl} ; 0.01 \%$ Tween-20; $0.01 \%$ NP-40; $200 \mu \mathrm{M}$ dNTPs (Promega products); $0.25 \mu \mathrm{m}$ primers and $2 \mathrm{U}$ Taq DNA polymerase (Promega products). PCR amplification was carried out as follows: 3 min at $94^{\circ} \mathrm{C}$ for predenaturation, then 30 cycles of amplification were repeated under the conditions of $94^{\circ} \mathrm{C}(30 \mathrm{~s}), 58^{\circ} \mathrm{C}$

Table 1. Primers used in the RT-PCR test

\begin{tabular}{|lcc|}
\hline $\begin{array}{c}\text { Genome } \\
\text { segment }\end{array}$ & Sequences of primer & $\begin{array}{c}\text { Length of } \\
\text { expected } \\
\text { product }\end{array}$ \\
\hline PS6 & 5'-AGTTC,TCAAA,GCTGA,GACGG-3' & $320 \mathrm{bp}$ \\
& 5'-ACGTG,CGATT,GGAAG,AGCTT-3' $^{\prime}$ & \\
PS9 & 5'-AGATC,TACTG,TGCTT,CACCT-3' & $223 \mathrm{bp}$ \\
& 5'-TAGTG,TGTCA,ATAGC,GTCCA-3' & \\
\hline
\end{tabular}


$(30 \mathrm{~s}), 72^{\circ} \mathrm{C}(60 \mathrm{~s})$ and the final extension at $72^{\circ} \mathrm{C}$ for 5 min by using a DNA thermal cycler (Minicycler-150, MJ). From each reaction tube, 5 to $10 \mu \mathrm{l}$ of PCR products were removed from beneath the oil layer and electrophoresed on $1.5 \%$ agarose gel (Gibco BRL). The gels were then stained with ethidium bromide and visualized under UV illumination and photographs taken.

\section{RESULTS}

\section{RT-PCR assay}

Two pairs of primers were used to amplify the purified viral genomic dsRNA as RT-PCR templates. Only one major product was obtained from each, and their lengths were $320 \mathrm{bp}$ (PS6) and 223 bp (PS9), respectively, according to the standard molecular weight markers (Fig. 1).

\section{Specificity}

To test the specificity of the GCHV by RT-PCR assay, other nucleic acid genomes including those of grass carp Ctenopharyngodon idellus, rare minnow Gobiocypris rarus, red drucian carp Carassiuus acwatus (red var.), common carp Cyprinus carpio, blunt snout Megabobrama amblycephala, loath Misgurnus anguillicamdatne, mitten crab Eriocheir sinensis, Penaeus monodon-type baculovirus (MBV) and cDNA of GCHV-873, a different strain of GCHV, were used as PCR templates and no specific amplification products were obtained. Therefore, the specificity shown by the RT-PCR amplification assay allows this method to be used to identify at least the GCHV-861 strain (Fig. 2).

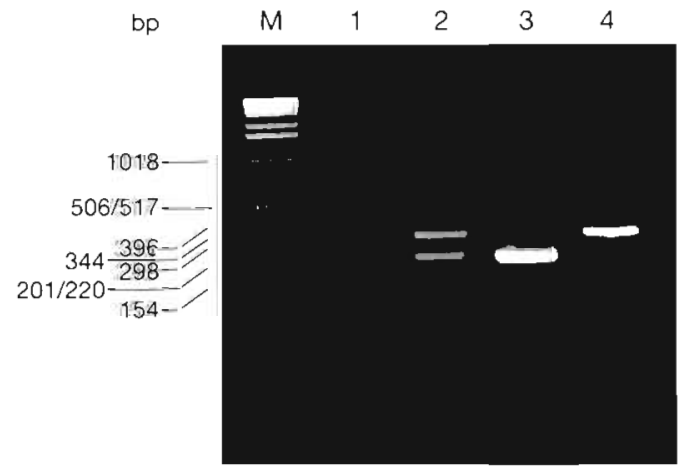

Fig. 1. Results of RT-PCR amplification of GCHV-861 dsRNA with different primers. M: $1 \mathrm{~kb}$ DNA ladder (Gibco BRL); Lane 1: negative control without template; Lanes 2 to 4 : RT-PCR products with primers PS6+PS9, PS9 and PS6, respectively

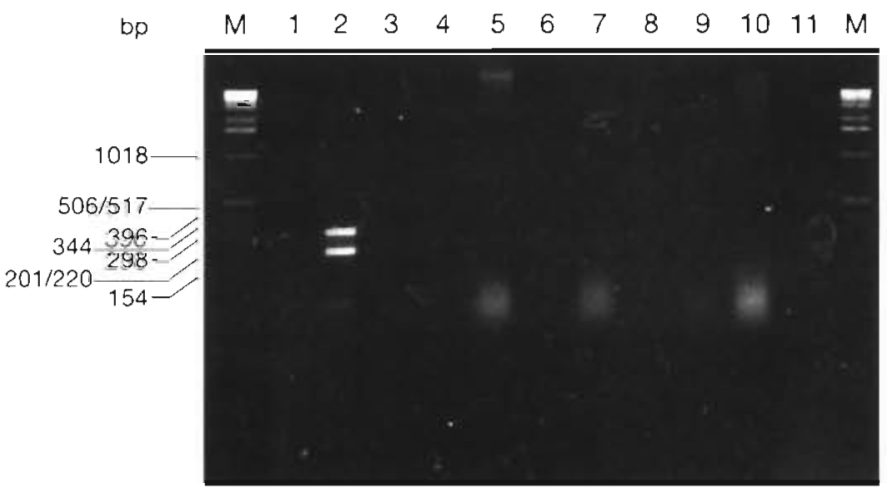

Fig. 2. Results of PCR amplification with different templates. $M: 1 \mathrm{~kb}$ DNA ladder (Gibco BRL); Lane 1: negative control without template; Lanes 2 to 3: CDNA synthesized from dsRNA of GCHV 861 and 873 strains, respectively; Lanes 4 to 11: genomic DNA of grass carp, rare minnow, red crucian, common carp, blunt-snout, loach, Eriocheir sinensis and MBV DNA, respectively

\section{Sensitivity}

To evaluate the sensitivity of the RT-PCR assay, RTPCR amplification was carried out with increasing amounts $(0.01 \mathrm{pg}$ up to $1000 \mathrm{pg})$ of purified GCHV-861 genomic dsRNA for 30 cycles by using primer PS6, followed by agarose gel electrophoresis. As little as $0.1 \mathrm{pg}$ purified genomic dsRNA could be visualized when $10 \mathrm{ml}$ of RT-PCR products from the $50 \mathrm{ml}$ total reaction volume were directly analyzed. Given more initital templates, they seemingly caused more nonspecific amplifications (Fig. 3).

\section{Direct detection}

GCHV could be directly detected in infected fish tissues by using crude tissue digests as RT-PCR initial

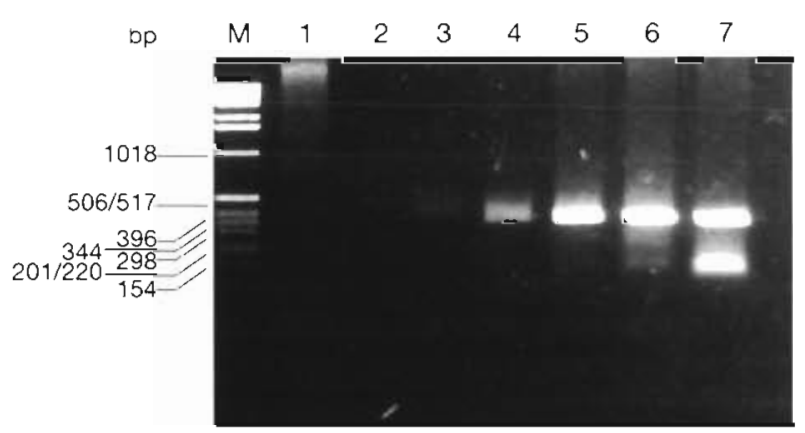

Fig. 3. Sensitivity of RT-PCR assay. M: $1 \mathrm{~kb}$ DNA ladder (Gibco BRL); Lane 1: negative control with genomic DNA of grass carp as template; Lanes 2 to 7 : RT-PCR products amplified with different amounts of purified genomic dsRNA of GCHV-861 strain $(0.01,0.1,1,10,100 \mathrm{pg}$ and $1 \mathrm{ng}$, respectively) 


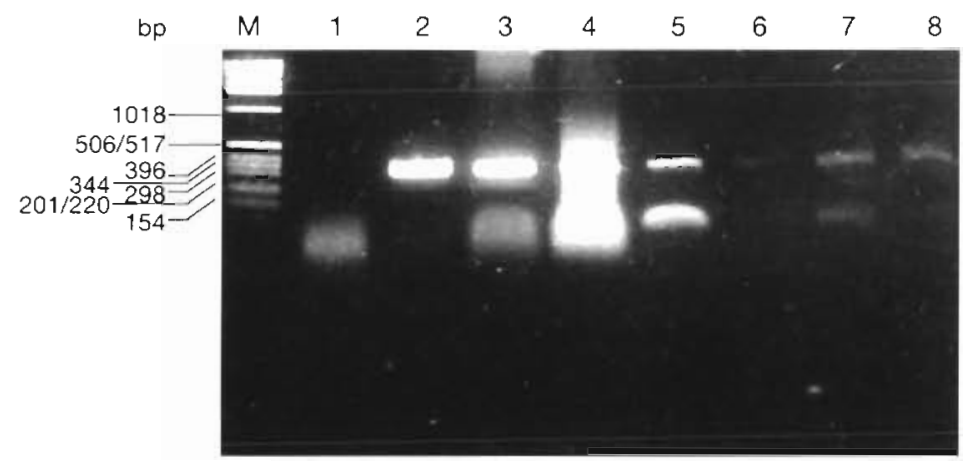

Fig. 4. Direct detection of GCHV in fish tissue by RT-PCR. M: $1 \mathrm{~kb}$ DNA ladder (Gibco BRL); Lane 1: crude tissue digestion of healthy grass carp as RT-PCR templates (negative control); Lane 2: plasmid DNA in which was cloned the 6th segment of GCHV-861 genome (positive control): Lanes 3 and 4 : crude digest of artificially infected grass carp tissue as RT-PCR templates; Lane 5: crude digest of artificially infected rare minnow tissue as RT-PCR templates; Lanes 6 to 8: crude digest of naturally infected grass carp tissue as RT-PCR templates

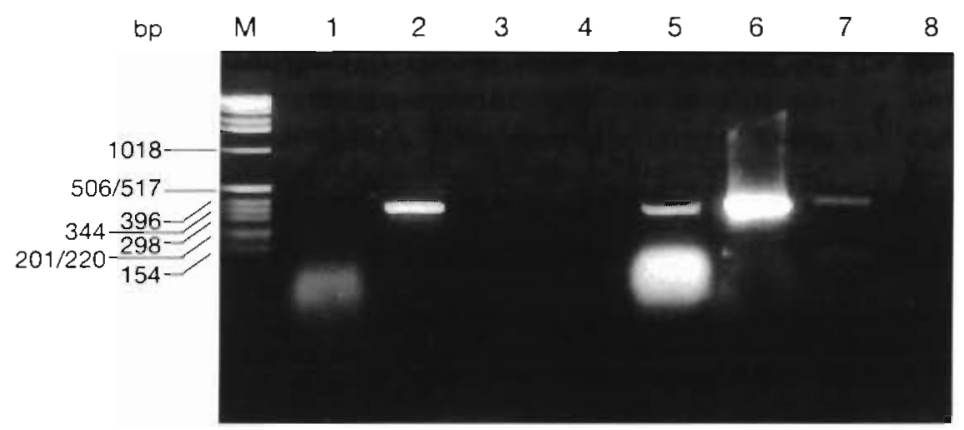

Fig. 5. Detection of GCHV-861 in tissues of artifically infected grass carp by RT-PCR. M: $1 \mathrm{~kb}$ DNA ladder (Gibco BRL); Lane 1: healthy grass carp tissue (RT-PCR negative control); Lane 2: plasmid template in which the 6th segment of GCHV861 genome was cloned (RT-PCR positive control); Lanes 3 to 8 : products of RT-PCR with viral dsRNA obtained from infected tish after $1,2,3,4,7$ and $23 \mathrm{~d}$, respectively

templates. The genomic dsRNA of GCHV-861 was detected in all the tissue samples examined. Furthermore, the naturally infected grass carp with typical hemorrhagic symptoms collected from our institute farm were detected by using the PS6 primer, but a weaker positive signal appeared. This implies that there were fewer templates in the natural diseased fish tissue samples or that the causal agent was a different one, and the sequence in the target region was not exactly the same, so it could not completely anneal with the specific primer and gave less specific amplification products (Fig. 4). Moreover, GCHV-861 could be detected directly in the fluids of infected cell cultures (data not shown).

After artificial infection, hemorrhages developed within 3 to $9 \mathrm{~d}$ and high mortality occurred in 4 to $7 \mathrm{~d}$ with the typical symptoms of infection with GCHV-861, i.e. 'hemorrhagic muscles' being evident. GCHV was detected in all the tissue samples except 1 of 5 convalescent carriers (Table 2 ).

The samples from fish with typical hemorrhagic symptoms in the acute disease phase gave stronger specific positive bands than did the others. Apparently, there were more virions in the stronger signal samples than in the others of the same weight (Fig. 5). There were no positive signals in some samples after a single round of PCR amplification, suggesting that there were not enough PCR products to be detected by agarose gel electrophoresis. A second round of PCR was performed by adding more Taq DNA polymerase, after which all of them gave visual bands which were virus specific (Fig. 6).

Moreover, the presence of virus in the liver, spleen, kidney, gill, intestine and muscle of the fish with typical hemorrhagic symptoms was detected by using primer PS6. The liver, kidney and intestine gave the strongest signals, muscle and gill tissues were somewhat weaker, and the spleen was the weakest. The liver also had a stronger non-specific amplification, perhaps caused by more genomic dsRNA in the sample extract (Fig. 7).
Table 2. Detection of RT-PCR in grass carp after their artificial infection with GCHV-861

\begin{tabular}{|lrrrccc|}
\hline & $\begin{array}{c}\text { Pre- } \\
\text { developing } \\
\text { period }\end{array}$ & $\begin{array}{c}\text { Developing } \\
\text { period }\end{array}$ & $\begin{array}{c}\text { Post- } \\
\text { developing } \\
\text { period }\end{array}$ & Control \\
\hline Sampling time (day) & 1 st & 2 nd & 3 rd & 4 th-7th & 23 rd & 1 st-23rd \\
No of samples tested & 5 & 5 & 5 & 15 & 5 & 10 \\
No. of positive samples & 5 & 5 & 5 & 15 & 4 & 0 \\
$\%$ positive & 100 & 100 & 100 & 100 & 80 & 0 \\
\hline
\end{tabular}

\section{DISCUSSION}

RT-PCR is a rapid, sensitive and highly specific detection method for fish viruses including GCHV and the technique has been successfully used in the detection and diagnosis of IPNV and SJNNV (Lopez-Lastra et al. 1994, Nishizawa et al. 1994). It can be easily performed with a DNA thermal cycler. 


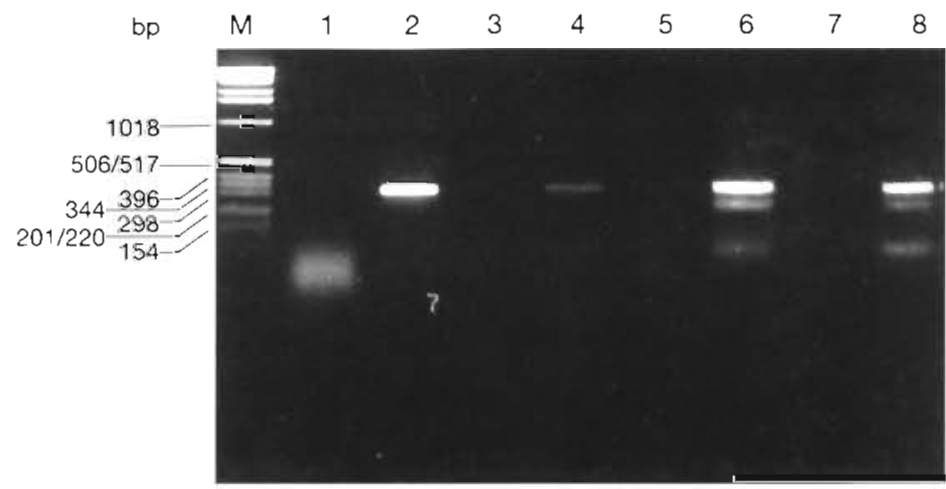

Fig. 6. Results of a 2 nd round of PCR amplification. M: $1 \mathrm{~kb}$ DNA. ladder (Gibco BRL); Lane 1: healthy grass carp tissues (RT-PCR negative control); Lane 2: plasmid template in which the 6th segment of GCHV-861 genome was cloned (RT-PCR positive control); Lanes 3, 5 and 7: RTPCR products after a single round of amplification; Lanes 4,6 and 8 : RT-PCR products after a 2 nd round of amplification

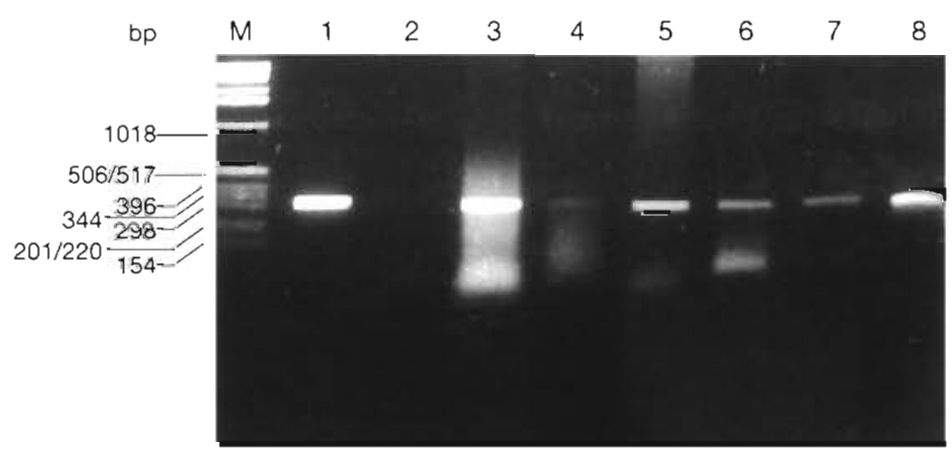

Fig. 7. RT-PCR amplification with dsRNA of GCHV from different tissues or organs of hemorrhagic grass carp. M: $1 \mathrm{~kb}$ DNA ladder (Gibco BRL); Lane 1: positive control; Lane 2: negative control; Lanes 3 to 8: RT-PCR products from liver, spleen, kidney, muscle, gill and intestines, respectively

The primers we synthesized can specifically detect the virus of GCHV-861 with either purified dsRNA or a crude tissue digest as initial templates. Each has only one major product. No products were obtained when nucleic acids other than GCHV-861 genomic dsRNA were used as RT-PCR templates. As little as $0.1 \mathrm{pg}$ purified viral genome could be detected when the amplification products were visualized by ethidium bromide-staining of agarose gels, which is much more sensitive than other techniques. Thus, the technique can be used in the diagnosis and identification of GCHV.

The results show that RT-PCR can detect not only purified virus, but also virions in the infected fish tissues directly. Furthermore, virions in carrier fish without any hemorrhagic symptoms can also be detected, which is important in preventing introduction of foreign causal agents. The present primers are successful when used for the detection of GCHV from naturally infected fish.

The RT-PCR technique described here can successfully detect GCHV-861 with the present primers, but not strain GCHV-873. Whether it can be applied to detect other GCHV strains needs further study. GCHV861 and GCHV-873 are completely different in their electropherograms of genomic dsRNA and major polypeptides (data not shown). Moreover, the mortality of diseased grass carp or rare minnow artificially infected with GCHV-861 is nearly $100 \%$, but there was no obvious cytopathic effect (CPE) in infected GCK or CIK cell lines. On the contrary, GCHV-873 produces a low mortality in infected fish and has a typical CPE. The results of RT-PCR amplification suggest that there are no homologous sequences at least in the target region of both viral strains

Up to now, several isolations of GCHV have been reported in China, but there has been no systemic study of the different GCHV isolates and the work of cloning and sequencing genes of GCHV has just been started. After obtaining more information on the sequences and molecular characteristics of other GCHV strains, we may be able to select a set of primers of a genome segment with high homology among strains which could lead to the common use of the RT-PCR detection protocol for the diagnosis and identification of GCHV.

In this study we have shown that GCHV is detectable not only in tissues from fish with typical hemorrhagic symptoms but from carrier fish as well. In experimentally infected fish, 4 of 5 had virus detectable by RT-PCR 23 d after infection, which indicates that the technique can be used to identify and select disease-resistant fish, a finding of significant value in the breeding of GCHV-resistant fish.

One other potential use of the technique described here, namely the detection of viral RNA extracted from fixed and embedded fish tissues as has been reported for infectious hematopoietic necrosis virus (Chiou et al. 1995), will allow retrospective studies of GCHV activity in China.

Acknowledgements. The work was partly supported by a state key project (857220902) and grants IFSA/2200-1 and $920 B 01$ from FEBL, the state key laboratory of Freshwater Ecology and Biotechnology. 


\section{LITERATURE CITED}

Chen Y, Jiang Y (1983) Studies on the morphological and physico-chemical characterization of the hemorrhagic virus of grass carp. KeXue TongBao (Foreign Lang Ed) 28:1138-1140

Chiou PP, Drolet B, Leong JC (1995) Polymerase chain amplification of infectious hematopoietic necrosis virus RNA extracted from fixed and embedded fish tissue. J Aquat Anim Health 7:9-15

Deng C, Chen H (1985) Study on the sensitivity of several fish cell lines to Grass Carp Reovirus. Acta Hydrobiologia Sinica 9(4):351-358 (in Chinese with English abstract)

Ding Q, Yu L, Wang X, Ke L (1991) Study on infecting other fishes with grass carp hemorrhagic virus. Chin J Virol 6(4):371-373 (in Chinese with English abstract)

Francki RI, Fauquet CM, Knudson DL, Brown F (eds) (1991) Classification and nomenclature of viruses. Arch Virol Suppl 2

Hetrick FM, Hedrick RP (1993) New viruses described in finfish from 1988-1992. Annu Rev Fish Dis 3:187-207

Jiang Y, Li Y, Li Z (1993) Comparison of the test conditions and features of two rapid viral detection methods. Proceedings of the $3 \mathrm{rd}$ Conference on Fish Diseases of China, The Chinese Fisheries Society, Wuhan, p 13 (in Chinese)

Ke L (1990) Characteristics of a new isolation of hemorrhagic virus of grass carp. Acta Hydrobiologia Sinica 14(2): 153-159 (in Chinese with English abstract)

Responsible Subject Editor: F. M. Hetrick, College Park, Maryland, USA
Lopez-Lastra M et al. (1994) A detection method for infectious pancreatic necrosis virus (IPNV) based on reverse transcription-polymerase chain reaction J Fish Dis 17:269-282

Mao S, Hang Q, Zhang N (1989) On pathogen of hemorrhage of grass carp. J Fish China 13(1):1-5 (in Chinese with English abstract)

Nishizawa TK et al. (1994) Polymerase chain reaction (PCR) amplification of RNA of striped jack nervous necrosis virus (SJNNV). Dis Aquat Org 18:103-107

Wang T, Chen H, Liu H, Guo W, Yi Y (1993) Purification of hemorrhagic virus of grass carp and the cDNA synthesis, cloning and sequencing of its genome. Annual Report of FEBL, International Academic Publishers, Beijing, $p$ $153-156$

Wang $T$, Chen $H_{1}$ Liu H, Yi Y, Guo W (1994) Preliminary studies on the susceptibility of Gobiocypris rarus to hemorrhagic virus of grass carp. Acta Hydrobiologia Sinica 18(2):144-149 (in Chinese with English abstract)

Yang G et al. (1991) Rapid serological diagnosis of grass carp hemorrhagic virus by coagglutination test using staphylococci protein A. J Fish China 15(1):27-33 (in Chinese with English abstract)

Ye X, Yang G, Luo Y (1989) Study of the detection method of grass carp hemorrhagic virus by immunoenzyme staining. Res Fish Dis 2:16-18 (in Chinese)

Zuo W, Qian H, Xu Y, Du S, Yang X (1986) A cell line derived from the kidney of grass carp. J Fish China 10(1):11-17 (in Chinese with English abstract)

Manuscript first received: May 28, 1996

Revised version accepted: October 9, 1996 